\title{
MARÍA Y EL MAR: IN MEMORIAN MARÍA ROSTWOROWSKI
}

\author{
Luis Miguel Glave*
}

Con gran regocijo se celebraron el 2015 los cien años de doña María Rostworowski. Más de una década ya había pasado desde que ella había cesado su activo y paciente trabajo con sus documentos y sus escritos, retirada a la vida familiar. Su prolífica existencia era todavía una seña de identidad para muchos investigadores, de varias generaciones, que la saludaron merecidamente. Ahora, poco después, nos ha tocado lamentar su partida y volver a reconocer su labor en tantos años de producción académica. Los numerosos y sentidos obituarios se han sucedido en el Perú, su país, y en todos los centros académicos de estudios andinistas. Pocas veces se encontrará tal unanimidad de criterio, tan sinceras expresiones de aprecio y agradecimiento. Es que lo que todos han tratado de expresar ha sido no solo la admiración por el trabajo académico de una colega que nos deja, sino el reconocimiento de ella como un símbolo.

María Rostworowski logró, sin proponérselo, convertirse en mujer símbolo. Por mujer investigadora pionera, cuando las mujeres no habían irrumpido para conquistar la academia como lo han hecho en las décadas recientes. Rompiendo esquemas, saltando barreras, abriendo sendas. Cuando en 1989 publicara sus trabajos acerca de la mujer en los Andes precoloniales, los comentarios que se vertían respecto de su aproximación a los estudios de género eran poca cosa comparados con la trascendencia que entonces tenía que fuera ella, la reconocida autora de innumerables estudios del mundo andino y el Tawantinsuyo, la que nos entregara sus aportes, siempre pacientemente documentados, relativos a las mujeres en esa época que conocía a las mil maravillas.

Siempre la acompañó un halo de brillo personal. Con modestia, cierta timidez, hablar pausado acompañado de cierta sonrisa y una dulce pasión por lo que contaba, aceptó generosamente participar en decenas de encuentros académicos y de difusión cultural. Las revistas peruanas y peruanistas que le solicitaban contribuciones siempre recibieron un sí por respuesta. Aceptaba gentilmente las invitaciones a publicar, sacaba de su artesanía variantes de los temas que la intrigaban y desafiaban. Máquina de escribir en ristre, apuntes, fotocopias y viejos libros en la mesa, producía variaciones de aproximaciones a temas sugerentes que acompañaba de transcripciones documentales producto de horas y horas de archivo. Su nombre firmaba contribuciones puntuales, aplomadas, directas y claras, que no por su sencillez dejaban de ser profundas y sobre todo parte de un programa vital para desentrañar las claves del entendimiento del mundo andino.

Decía que tenía un largo pasado, entendía la identidad en el amor por esa historia que no inventaba ni presumía conceptos. Alguna vez le titularon una entrevista: "Garcilaso miente". Polemizaba con las crónicas, amparada en su novedosa y perspicaz lectura de viejos títulos de propiedad, procesos judiciales, informaciones de oficio y parte, informes administrativos y fiscales, las "visitas" a las que ella contribuyó a hacer famosas en la historiografía.

En los años ochenta del siglo pasado y todavía en los noventa, llegaba puntualmente a la hora de abrir la vieja casona donde tiene su sede el Instituto de Estudios Peruanos, institución que ayudó a fundar y a darle un sello. Los trabajos que le darían justa fama se fraguaron en su despacho de la casa del IEP en la calle Arnaldo Márquez de Jesús María en Lima. A fines de los ochenta y comienzos de los noventa llegaba en un juvenil Mitsubishi que aparcaba frente a la fachada de la añosa gran casa señorial devenida en centro de estudios. Se refugiaba en su despacho lleno de fotocopias, fichas, notas, cuadernos y libros. Su máquina de escribir comenzaba a correr de inmediato y su tip tip firme y continuo se podía sentir en los pasillos. Solo interrumpía su trabajo cuando alguien tocaba su puerta a pedirle algo de su sabiduría. No la negaba nunca. Pasado el mediodía volvía a su piso en Miraflores, considerando que parte importante del tiempo también había que darlo a los seres queridos.

\footnotetext{
* Instituto de Estudios Peruanos, Lima, Perú; El Colegio de América, Universidad Pablo de Olavide, Sevilla, España. Correo electrónico: lmglave@hotmail.com
} 
Fruto de su romance con la historia andina en 1953 apareció su libro sobre Pachacutec Inca Yupanqui. Pasarán décadas y volveremos a él siempre. No publicará nuevos aportes hasta 1960. Estaba investigando. En esa década comenzará a sacar cortas y precisas contribuciones. Acerca del parentesco, los cacicazgos, las etnias. Temas como las tierras reales de los incas (1962) o los pesos y medidas antiguos (1958) los llevó a congresos tanto en el Perú como en el extranjero. Los resultados de sus investigaciones aparecieron en revistas locales como la del Archivo Nacional, Histórica y Nueuacoronica. La medición de las tierras, la posesión de las mismas, le interesaron a partir de documentos que veía con nuevos ojos, como las composiciones de tierras y títulos de propiedad que descansaban en el Archivo Nacional. Son temas humildes a la vez que iluminadores. Sus aportes iban siempre con transcripciones documentales.

En los años setenta se hará prolífica y junto con ensayos cortos dará a luz, siempre en el Instituto de Estudios Peruanos, los libros que la convertirán en un faro de la etnohistoria andina: Etnía y Sociedad (1977), Señoríos indígenas de Lima y Canta (1978) y Recursos naturales renovables y pesca (1981). $\mathrm{Su}$ foco de observación fue la costa y el mar. En sus escritos vemos pescadores, derroteros marinos, embarcaciones, las delicadas "lomas" efímeras de los cerros del desierto. Habrá que recordar a María frente al mar, con su mirada al sol de poniente que debía ver reflejado en los documentos que engreía con su atención. John Murra se encargaba de hacer notar a todos los que admiraban su modelo del control vertical de pisos ecológicos, que era el paciente trabajo de María el que servía de "control" al modelo, al enfocar su mirada en la costa y otras formas de complementariedad. Su ensayo sobre los mercaderes de Chincha (1970), el intercambio y las rutas marítimas, los señoríos de la costa, el intercambio de Spondylus, eran como dardos simples y eficaces para complementar lo que Murra había trabajado en cuanto a tierras de arriba y de abajo en su modelo vertical. En 1989 reeditó su libro Etnía y sociedad como Costa peruana prehispánica. En 1993 recogió varios de sus dispersos ensayos en un volumen de Ensayos de historia andina: elites, etnias, recursos.

En 1983 había dado a luz un libro, donde avanzaba sobre sus estudios acerca de la religión y la política en el Perú prehispánico, Estructuras andinas del poder. Todo lo que desde entonces publicó, siempre a la manera de cortos trabajos documentados, preparaba su síntesis que la convirtió en "best seller" con su Historia del Tawantinsuyo (1988).

En los años noventa se dejó seducir por nuevas derivas, siempre con el mismo estilo de trabajo y sus publicaciones ya gozaron del beneplácito de muchos compradores, aunque no tantos lectores probablemente. Pachacamac y el Señor de los Milagros (1992) y su Francisca Pizarro una ilustre mestiza (1989). Con el tirón de su éxito editorial, la casa editora fabricó varios tomos de obras completas desde el 2001, que ya escaparon a su época de producción activa que se cerró cuando editaron un segundo volumen de Ensayos en 1998.

Fotocopias de documentos que almacenó de sus investigaciones, de una estancia en la sala de investigaciones de la Casa Lonja de Sevilla donde está el Archivo General de Indias, de repositorios andinistas de aquí y allá y de algunos archivos regionales. Cuadernos, ediciones de crónicas y colecciones documentales adornaban un delicado desorden en su despacho. Esta nota quiere ayudar a que se le recuerde así: paciente y silenciosamente, entregada al placer incomparable de dialogar con las fuentes, mirar los detalles, tejerlos hasta hacer inteligible lo que encubren los formatos de la intrincada papelería administrativa colonial, mirando sus papeles como si al mar observara porque al fondo se encontrarían las respuestas a su infinita curiosidad. Si se pudiera, seguramente cien años más viviría solo por seguir en esa labor, donde ponía todo su amor a su maravillosa tierra y su siempre sorprendente y potente historia. 


\title{
REINER TOM ZUIDEMA ${ }^{\dagger}$ (1927-2016)
}

\author{
Mario A. Rivera*
}

El miércoles 2 de marzo dejó de existir en Urbana, Illinois, el profesor emérito de la Universidad de Illinois y miembro del Comité Editorial de Diálogo Andino, Dr. R. Tom Zuidema. Renombrado antropólogo, figura clave en el desarrollo de los estudios de las culturas andinas, fue también un profesor dedicado a compartir sus logros científicos y contribuir en la formación de centenares de estudiantes. Su espíritu de educador incluyó la Universidad de Tarapacá, donde llegó en 1995 para dictar un seminario en conjunto con quien escribe estas líneas, para los estudiantes de Historia y Geografía, evento que fue organizado por el Centro de Estudiantes de esa carrera. Etnohistoriador por excelencia, conocí a Tom por intermedio de Donald Lathrap allá por la década de 1960. Siempre muy afable, colaborador y estudioso, aprendí mucho de él sobre los grandes temas del mundo andino, especialmente respecto de las posibles explicaciones de la etnohistoria para las incógnitas que muchas veces producen las investigaciones arqueológicas. De bajo relieve personal, tranquilo y mesurado, paciente y dedicado, y por sobre todo un gran lector, Tom nació en Holanda en 1927. Comenzó sus estudios de administración en la Universidad de Leiden en la década de 1950 porque quería ser antropólogo para trabajar en las Indias Orientales Neoholandesas. Sus profesores, prominentes figuras del estructuralismo holandés, fueron Jan Petrus Benjamin de Josselin de Jong y Patrick Edward de Josselin de Jong, ambos especialistas en regionalismo indonesio. Al terminar la carrera Indonesia logró independizarse, de manera que Tom no pudo ejercer allí. En 1949 Tom cambió sus intereses hacia lo andino, especialmente el tema incaico, trasladándose a Madrid, posiblemente influenciado por los aportes etnográficos de Levi Strauss sobre las comunidades Ge y Bororo de la cuenca amazónica. Obtuvo así su primer doctorado en la Universidad de Madrid en 1953 con su tesis "La organización social y política Incaica según las fuentes españolas". En los años 1956-64 mientras seguía sus estudios de postgrado fue curador de las colecciones de Sudamérica, Norteamérica y de
Siberia en el Museo del Estado, Leiden, Holanda. En 1964 obtuvo su segundo doctorado de la Universidad de Leiden con su tesis "The Ceque System of Cuzco: the Social Organization of the Capital of the Inca".

$\mathrm{Al}$ concluir sus estudios en Leiden, Tom aceptó un puesto en la Universidad San Cristóbal de Huamanga, Ayacucho, Perú, para enseñar diversos aspectos de la cultura andina y donde permaneció desde 1964 a 1967. Posteriormente en 1967 ingresó al Departamento de Antropología de la Universidad de Illinois en Urbana, donde ejerció toda su carrera hasta su retiro en 1994. Una de sus mayores contribuciones al conocimiento del mundo andino, especialmente Inca, han sido sus estudios centrados en la organización social y política de Cuzco mediante el estudio del sistema de ceques, incluyendo las divisiones dual y cuadripartita. Estos análisis representan el marco de referencia para las relaciones políticas, sociales y aun, rituales de los grupos descendientes de los reyes Inca (panacas), así como de los descendientes no nobles con estatus de residentes (ayllus) del Cuzco. La contribución de Zuidema también incluye aspectos de la civilización andina en relación con temas de parentesco, calendario Inca, astronomía incaica, sistema de registro y contabilidad (quipus). La producción de Tom Zuidema es enorme. Su tesis sobre el sistema ceques del Cuzco fue publicada en inglés en 1964 (Trans. Eva M. Hooykaas. Archives Internationales d'Ethnographie 50. Leiden: Brill.), y posteriormente en italiano en 1971 y en español en 1995. Otros libros importantes son:

Etnologia e storia. Cuzco e le strutture dell'impero Inca (Torino, Einaudi, 1971), La civilisation Inca au Cuzco (Essais et conferences) (1985, Presses Universitaires de France) Reyes y guerreros: Ensayos de cultura andina (1989, Lima, Fomciencias), Inca Civilization in Cuzco (1990, Trans. Jean-Jacques Decoster. Austin: University of Texas Press), y recientemente El calendario inca. Tiempo y espacio en la organización ritual del Cuzco. La idea del pasado (2011, Lima: Fondo

\footnotetext{
* Universidad de Magallanes, Punta Arenas, Chile. Field Museum of Natural History, Chicago, Illinois. Estado Unidos. Correo electrónico: marivera41@gmail.com
} 
Editorial del Congreso del Perú), compendio magnífico acerca de la cultura incaica.

En 2013 Zuidema fue incorporado a la Galería de Excelencia del Colegio de Artes y Ciencias Liberales de la Universidad de Illinois. Fue también profesor en el Centro de Estudios Avanzados de la misma Universidad y profesor visitante en varios centros de excelencia académica, entre las cuales figuran Universidades de Harvard, Michigan, Paris X Nanterre, Pontificia Universidad Católica de Lima, Universidad de Texas en Austin, Facultad Latinoamericana de Ciencias Sociales en Quito y el Colegio de Francia, Paris. También fue Director Asociado de la Escuela Práctica de Altos Estudios, Paris y Visiting Scholar en el Getty Centre for the
History of Art and the Humanities, Curador de las Colecciones de Sud y Norteamérica del Rijksmuseum voor Volkenkunde, Leiden, Holanda.

Por designación de la Reina Juliana de Holanda se incorporó como miembro de la Academia de Ciencias de ese país, y entre varias distinciones, recibió la medalla François Premier del Collège de France. En 1980 la Fundación Guggenheim lo designó como Fellow. En Perú, fue distinguido como doctor honoris causa en la Pontificia Universidad Católica (1993), Universidad Nacional Mayor de San Marcos (2003), y Universidad Nacional San Antonio Abad de Cusco (2006). En 2008, el Gobierno peruano le condecoró con la Orden del Sol en el grado de Comendador.

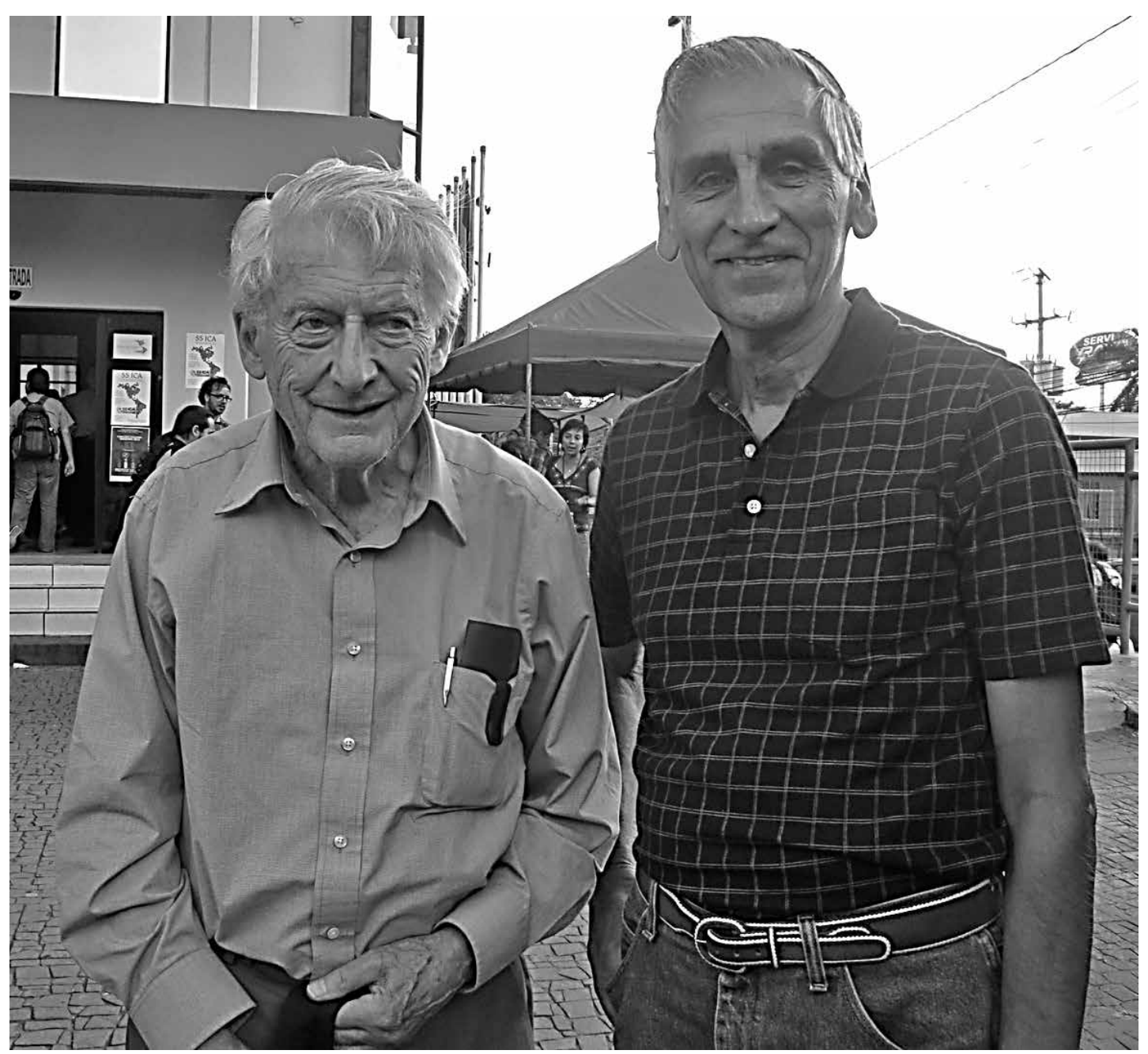

Con Tom Zuidema desaparece tal vez el último representante de la más esplendorosa generación de estudiosos del mundo andino. 